\title{
Automated Bridal Veni Making
}

\author{
S.Vijayachitra, Hema Priya Dharshini.M, Nandhakumar.P, Nanthini.K, Ajith Kumar.M
}

\begin{abstract}
The presented work is related to tying of flowers and more specifically it deals with knotting mechanism using Pneumatic actuator driven by a Servo motor. Veni making using different kinds of flowers are preferred by most of the women during their festival occasions. Each type of flower has different processes and methods for tying. Various types of flowers used for veni making are Sampangi, Jasmine and Roses. Here the flowers are tied one by one with gripper and servomotor unit using pneumatic actuator in order to make a bridal Veni. When it is done manually, a person has to tie each and every flower to produce Veni in different designs. There is no known mechanism in which the veni can be automated. Generally there are many automated mechanisms for tying a bunch of flowers for easier transportation or storage, whereas an automated mechanism for bridal veni making is not known. This proposed work provides an automated process for bridal veni making using pneumatic pistons, Servomotor with gripper unit and relay circuit.
\end{abstract} unit.

Keywords: pneumatic actuator, relay unit, servo motor, gripper

\section{INTRODUCTION}

Traditional process of Bridal Veni making using flowers is a day to day affair in many parts of India. There are several types of flowers that are manually tied by hand using different procedures. Some type of bridal veni using different varieties of flowers used by women during marriage functions and some traditional festival occasions is as shown in the Figure 1.

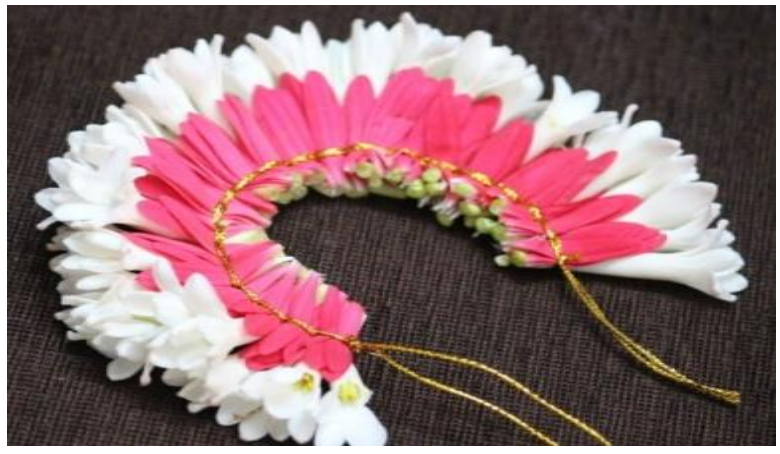

Figure 1: Bridal Veni

In many parts of India, each type of flower has different processes and methods for tying. With respect to flowers such as Sampangi, Jasmine, Roses and other flowers that are used to make bridal Veni. Here the flowers are gathered together and knotted in a specific way to make a Veni. When it is done manually, a person ties each and every flower to produce Veni in different designs. There is no known mechanism where the veni can be automated. There are several automated mechanism for tying a bunch of flowers for easier transportation or storage, whereas an automated mechanism for bridal veni making is not known. An idea of proposing a suitable project is by to use pneumatic pistons and servomotor along with gripper. Nano Aurdino is used for coding and relays for actuating the pneumatic cylinders. Relays are activated by 5V DC supply to convert the $230 \mathrm{~V}$ AC to $5 \mathrm{~V}$ DC supply. The proximity sensor is used to ensure the thread in the correct position. The prototype is working in the sequence order based on the program commands. Still now there no existing machine for bridal veni making and bridal veni is now made by hands Figure 2 shows the veni making by hand.

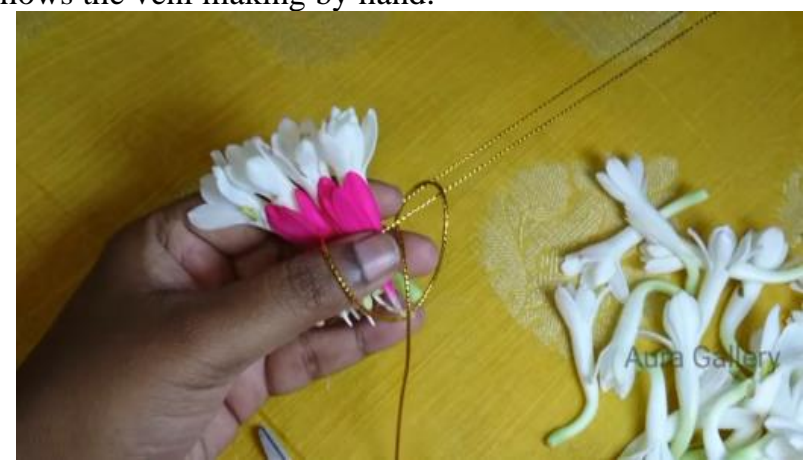

Figure 2: Veni making by hand

The major objectives of the proposed project are listed as follows:

* To provide an automated process for bridal veni making using pneumatic actuators, Servomotor with gripper unit and relay circuit.

* To reduce the manual work. 


\section{PROPOSED METHODOLOGY: BRIDAL VENI MAKING}

\section{a. Block Diagram}

The following Figure 3 shows the overall block diagram of the proposed work.

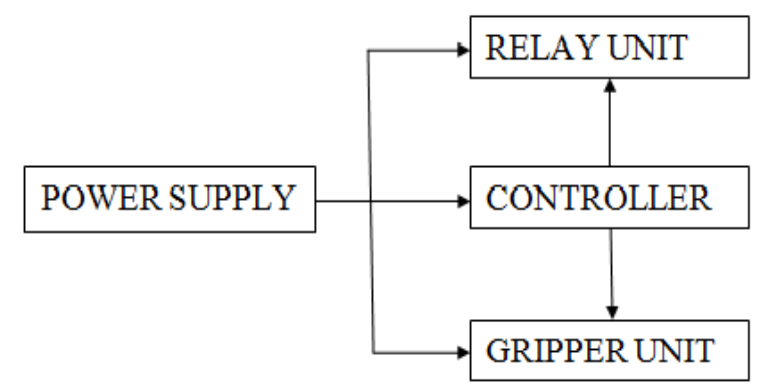

Figure 3 Block diagram of automated bridal veni making

To do the process of veni making, the following units are to be carried out:
i) Relay unit

ii) Gripper unit

In the gripper unit there are five pneumatic actuators and grippers are used. To tie the flowers thread bundle is attached to the gripper I. Based upon the programming done in the nano aurdino the actuators and grippers will be functioning. After some few seconds pneumatic actuators II moves to gripper I and picks the thread. Here the thread along with Pneumatic actuator II goes to its initial position. Now pneumatic actuator III moves forward and gripper II now picks the thread. Then Pneumatic actuator III moves to its original position. Now the pneumatic actuator IV holding thread moves forward and the pneumatic actuator $\mathrm{V}$ picks the thread. Finally, the pneumatic actuator V moves to gripper I. And now gripper I picks the thread. By this time the one cycle will be completed and first knot is being completed. This process is to be continued by 'n' number of times to complete the veni. Finally in this way, the bridal veni is made automatically.

\section{b. Steps to be Followed:}

To develop the hardware for bridal veni making, there are several hardware accessories are to be arranged as shown in Figure 4. Thread arrangement for typing the flowers, grippers for holding the flowers in their appropriate position, servomotor, for moving the piston assembly and four numbers of pneumatic cylinders for actuating the veni making process. These four pneumatic cylinders are properly positioned as per the sequential operation of bridal making processes.

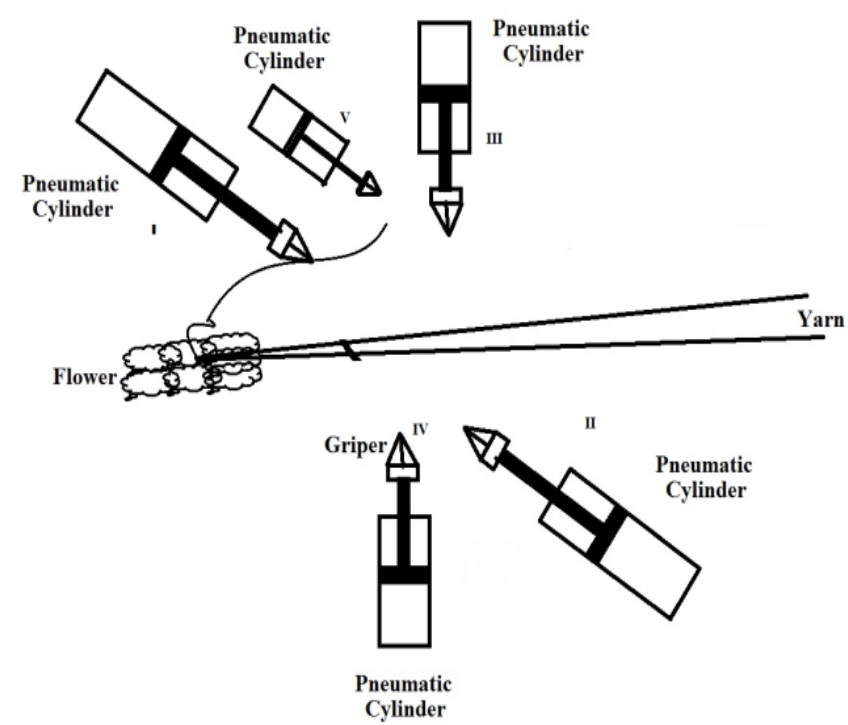

Figure 4 Hardware Arrangement of prototype

\section{c. COMPONENTS DESCRIPTION}

Various components required for this method with its purpose is described as follows

i) Transformer - Transformer could be a static device that converts wattage from one circuit to a different while not ever-changing its frequency. It improves (or Step down) the amount of AC Voltage and Current. It works on the principle of mutual induction of 2 coils or physicist Law's of magnetic attraction induction.

ii) Servo Motor - A servo motor is a device which may push or rotate an object with high precision. If it needs to rotate any object at some specific angles or distance, then it is necessary to employ the servo motor.

iii) Nano Aurdino Board - Aurdino Nano is a tiny, compatible, versatile and bread board friendly Microcontroller board, developed by Aurdino.cc in Italy, supported ATmega328p.

iv) Pneumatic Actuator - Pneumatic actuator could be mechanical devices that use compressed gas working on a piston within a cylinder to move a load on a linear path. In contrast to their hydraulic alternatives, the operational fluid during a gas mechanism is just air, and therefore leakage doesn't drip and contaminate close areas. The most standard type of pneumatic mechanism consists of a piston and rod moving within a closed cylinder. This mechanism vogue is sub-divided into 2 sorts supported the operational principle: single acting and double acting. Single-acting cylinders use one air port to permit compressed gas to enter the cylinder to move the piston to the specified position, additionally as an inside spring to come back the piston to the "home" position once the air pressure is removed. Double-acting cylinders have an air port at every end and move the piston forward and back by alternating the port that receives the high pressure air. Figure 5 shows the schematic illustration of two cylinder piston.

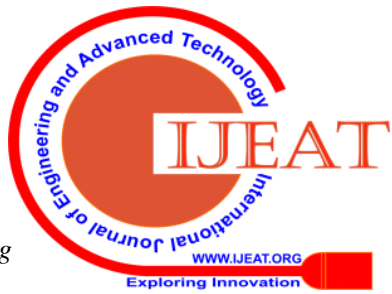




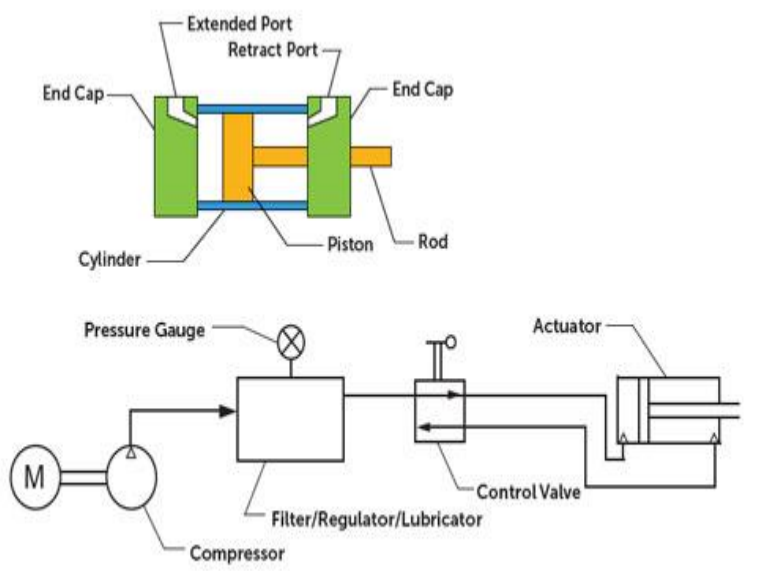

Figure 5: Schematic representation of two cylinder piston

\section{RESULT ANALYSIS}

The following figure 6 shows the Prototype development model for bridal veni making.

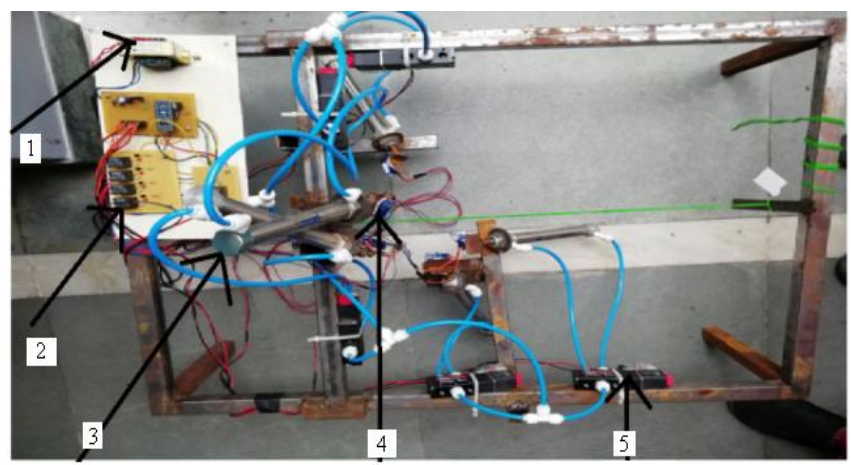

\section{Transformer}

2.Relay

3. Pneumatic cylinder

4.Servo motor

5. Current to pressure convertor

Figure: 6 Prototype Model of Bridal Veni Making

Based on trials for multiple inputs factors, it is observed that this is an ideal method for veni making by using pneumatic actuator along with servomotor. The following Table-1 shows the effectiveness of the proposed work.

Table-1: Effectiveness of the proposed work

\begin{tabular}{|c|c|c|}
\hline Parameter & $\begin{array}{c}\text { Manual } \\
\text { Method }\end{array}$ & $\begin{array}{c}\text { Proposed } \\
\text { Method }\end{array}$ \\
\hline Time (min) & $10 /$ veni & $50 /$ veni \\
\hline Accuracy & $100 \%$ & $<100 \%$ \\
\hline
\end{tabular}

\section{CONCLUSION}

The proposed project proved as an efficient solution for bridal veni making. It had to gather large amount of data pertaining to the veni making for research to know which combination of different factors yields the best results.

The proposed system opens up the door to a whole new range of commercially sold products which can be economically sold to all sections of the demographic. Further research could lead to advancements in features like adding desired colourings of veni to attract all people to use this advanced technique.

\section{REFERENCES}

1. Asian Journal of Applied Science and Technology (AJAST), Vol 1, No.3, pp- 17-19, April 2017.

2. Manoj Botre, "Design and Implementation of Pick and Place Robotic Arm," International Journal of Recent Research in Civil and Mechanical Engineering (IJRRCME), Vol. 2, No. 1, pp: 232-240, year 2015.

3. J.A. Marchant, M.J. Street, P. Gurney, J.A. Benson, "Design and testing of a servo controller for pneumatic cylinders Proc Inst Mech Eng E”, No.203, pp.21-27, Nov 1989.

4. B.O.Omijeh, R.Uhunmwangho, M.Ehikhamenle, "Design Analysis of a Remote Controlled Pick and Place Robotic Vehicle", International Journal of Engineering Research and Development, Vol.10, pp.57-68, May 2014.

5. Rakesh.N, Pradeep Kumar.A, Ajay.S, "Design and Manufacturing of Low Cost Pneumatic Pick and Place Robot", International Journal of Scientific and Technology Research, vol.2, No.8, Aug 2013.

6. Saifuldeenabed Jebur, Prabhat Kumar Sinha and Ishan Om Bhargava, "Advancement and Stimulation of Five Degree of Freedom Robot Lever Arm", International Journal of Mechanical Engineering \& Technology (IJMET), Vol.5, No.3, pp.20-30, 2014.

7. Maha M. Lashin Mechanical Engineering Department, Shoubra Faculty of Engineering, Banha University, Egypt "Different Applications of Arduino" International Journal of Mechanical Engineering and Technology (IJMET), Vol.5, No.6, pp.36-46, June 2014.

8. Kimura, T, Hara, S and Tomisaka, T. 1996. "H-infinity control with minor feedback for a pneumatic actuator system". In Proc. of 35th IEEE Conf. on Decision and Control (CDC) Vol.3, pp.2365-2370. Kobe, Japan

9. Haxthausen, A.E."Developing a Domain Model for Relay Circuits", International Journal of Software and Informatics, Vol.2, No.2-3, pp.241-272, 2009. 